\title{
ORALIDAD EN LAS BITÁCORAS DE VIAJE 2.0*
}

\author{
ORALITY IN THE TRAVEL BLOGS
}

María Enriqueta PÉREZ VÁZQUEZ

Universidad de Bolonia-Forlí

\section{RESUMEN:}

El objetivo de este trabajo es el análisis de los rasgos típicos de la oralidad en un determinado tipo de texto escrito: el de los blogs turísticos, usando un corpus de 25 bitácoras digitales en español. En este estudio se tratará el estilo, el léxico, las características morfosintácticas propias del lenguaje oral y coloquial, así como estrategias comunicativas de las nuevas tecnologías para suplir la oralidad.

PALABRAS CLAVE: lenguaje turístico, registro coloquial, oralidad, blog turístico.

\section{ABSTRACT:}

The aim of this paper is to analyze the typical features of orality in a specific type of written text, that is digital travel blogs, by using a corpus of 25 weblogs written in Spanish. In this article, we will study the style, vocabulary and morphosyntactic characteristics of spoken and colloquial language, as well as the communication strategies employed to replace orality.

KEY WORDS: tourism language, colloquial level, orality, tourism blog.

* Este trabajo nace en el ámbito del proyecto FARB, dirigido y coordinado por el profesor Félix San Vicente (Universidad de Bolonia). 


\section{INTRODUCCIÓN}

Este trabajo pretende estudiar los rasgos prototípicos de la oralidad presentes en un soporte escrito, el de $\operatorname{los}$ blogs ${ }^{1}$ de turismo. El estudio tratará también rasgos típicos de la coloquialidad, dado que, por excelencia, es el registro propio de la oralidad y, como se mostrará, la mayoría de estos pertenecen a la coloquialidad tanto del canal escrito como del oral; se tratarán también características propias del discurso conversacional, dado que es el género típico de la oralidad.

En primer lugar se describirá brevemente el corpus con algunas pinceladas sobre las características de cada uno de los blogs; a continuación, se repasarán brevemente las características del género textual al que pertenecen estas plataformas, relacionándolo con los libros de viajes y las guías turísticas. En segundo lugar, se hará una reflexión sobre los registros y los canales de comunicación, sobre la oralidad y la coloquilidad, pues se parte de la idea de que el binomio oral/escrito se refiere al canal de comunicación y que no debe confundirse con conceptos como «coloquial», que es un registro, o con «conversacional», que es un tipo de discurso. Por último se exponen, a través del análisis de los blogs del corpus, las características lingüísticas típicas o recurrentes de la oralidad, en relación al concepto de «escrituridad», presentes en este género escrito y con referencias a las nuevas tecnologías.

\subsection{El corpus}

El corpus está formado por 25 blogs en español, según los criterios de frecuencia de visitas (los 25 más visitados de este género en lengua española), y de calidad según una reseña del diario El País, de la sección El Viajero (10-09-2012). Se han analizado las diez entradas más recientes de cada uno de estos blogs.

Los blogueros de estas 25 bitácoras son periodistas o grandes apasionados de viaje cuya actividad ha sido denominada «periodismo ciudadano» o «periodismo participativo» (Álvarez Nobell, 2010: 27) o lo que Varela (2005) identifica como «periodismo 3.0».

Viajablog: Blog coral de viajes dedicado a dar consejos para preparar viajes, rutas, aventuras y escapadas por el mundo (www.viajablog.com).

El rincón de Sele: Información práctica y experiencial de más de 80 países del mundo (www.elrincondesele.com).

3Viajesaldia: Blog coral. Combina la información práctica, los reportajes, las experiencias personales y las novedades del mundo 2.0 (www.3viajes.com).

\footnotetext{
${ }^{1}$ Los blogs son sitios web en el que uno o varios autores publican cronológicamente textos o artículos, apareciendo primero el más reciente, donde el autor conserva siempre la libertad de dejar publicado lo que crea pertinente y donde suele ser habitual que los propios lectores participen activamente a través de sus comentarios. Sobre la fecha de aparición de los blogs no existe un consenso entre los expertos. La primera fecha que se da es 1993 (What's new de Mosaic: navegador gráfico para visualizar páginas web), y la más tardía 1997 (año en el que se acuña el término «weblog» por parte de Jorn Barber en su sito Robot Wisdom). Sobre la fecha de aparición de los primeros blogs de turismo, en cambio, no he hallado noticias.
} 
Ciudadano del Mundo: Relato subjetivo y pasional de los viajes del bloguero y las novedades del mundo 2.0 (www.ciudadanoenelmundo.com).

Paco Elvira Paco: Blog con cientos de reportajes de viajes publicados. Habla de fotografía, viajes y cocina (www.pacoelvira.com).

El próximo Viaje: Experiencias de viajes en primera persona, noticias, tendencias, destinos, recomendaciones, gastronomía y consejos originales para viajar (www.elproximoviaje.com).

Dry Martinez: Reportajes y fotos de viajes por todos los países del mundo. Naturaleza, cultura, patrimonio, literatura y tradiciones para encontrar y disfrutar la emoción del viaje (www.drymartinez.net).

Blog de viajes: Reflexiones sedentarias sobre viajes, turismo, comunicacion y ciencias sociales (www.blogdeviajes.com.ar)

El Pachinko: Blog de viajes con niños. Experiencias, visitas recomendadas y consejos para organizar viajes en familia (www.elpachinko.com).

Trajinando por el mundo: Blog de viajes: aventuras, destinos, visitas y consejos viajeros de la mano de una mochilera experimentada (http://trajinandoporelmundo.com).

Xixerone.com: Artículos para inspirar a viajar, a hacer fotografías con información sobre viajes. El bloguero es experto en marketing online, crítico con las compañías aéreas o con un destino (www.xixerone.com).

Mis viajes por ahí: Relatos personales de viaje de la bloguera, con información y consejos para cualquier viajero y las anécdotas vividas en cada lugar (www.misviajesporahi.es).

Viajes, rock y fotos: El bloguero describe y fotografía el mundo, pero todo queda pasado por un tamiz: el de su amor al rock (www.viajesrockyfotos.com).

Ventana o pasillo: Escrito por un histórico del periodismo de viajes, tiene una gran carga crítica y un gran capacidad de análisis. (http://www.ocholeguas.com).

Turiskopio: La bloguera habla de viajes, nuevas tecnologías, marketing 2.0 y redes sociales (www.turiskopio.com).

Viajando por ahí: La bloguera escribe y viaja por el mundo de manera pausada, y lo cuenta de una manera personal y llena de emociones (www.viajandoporahi.com).

A Salto de Mata: Los viajes y la experiencia turística vistos desde la silla de ruedas del bloguero (www.asaltodemata.com).

Vagamundos: El bloguero es un viajero independiente que recorre lugares fuera de circuito de forma pausada (www.vagamundos.net).

Guias Viajar: El blog recoge fundamentalmente información práctica, datos, curiosidades históricas, noticias del sector y reportajes fotográficos. (www.guiasviajar.com).

Viajando con Diego: Este blog es un canal de vídeos dirigido a viajeros activos que buscan alternativas a las guías de viaje convencionales para ver destinos y actividades (www.viajandocondiego.com).

Jordi Busqué: El blog se subtitula «las aventuras de un fotógrafo que fue astrofísico». El bloguero escribe con un agudo sentido del humor, analizando el mundo desde la perspectiva de un científico (www.jordibusque.blogspot.com.es).

Hombre Lobo: Un videoblog en el que se ofrece información sobre numerosos destinos, se habla de marketing 2.0 y de redes sociales (www.hombrelobo.com).

El fotógrafo viajero: El bloguero ofrece detallados reportajes fotográficos con informaciones técnicas (www.elfotografoviajero.com). 
Crónicas de una cámara: Bitácora de un fotógrafo de viajes con numerosas imágenes de los países que visita, acompañadas por relatos y anécdotas de esos viajes (www.ignacioizquierdo.com).

Flapy in Japan: El blog, con un estilo informal y desenfadado, acerca al lector a un mundo tan lejano y desconocido para todos como es el Lejano Oriente (www.flapyinjapan.com).

Gastronotas de Capel: El bloguero, crítico gastronómico, muestra sus viajes de carácter fundamentalmente gastronómico, recetas, cocineros y otras curiosidades reales y en la red (http://blogs.elpais.com/gastronotas-de-capel.es).

EI Viajero Astuto: Informaciones prácticas y curiosas del mundo y ofertas de viajes (http://blogs.elpais.com/viajero-astuto/).

Turistario: El blog ofrece una gran colección de curiosidades viajeras, recomendaciones y consejos de todo tipo, destinos, tendencias y souvenirs (http://blogs.elpais.com/turistario).

Kilómetro Sur: Blog de viaje por Iberoamérica. El autor se interesa especialmente por el contacto con la población, las relaciones humanas, las costumbres y características de cada pueblo (http://blogs.elpais.com/kilometro-sur/).

Guisante Verde Project: Blog de viajes especialmente preocupado pr mostrar la historia de cada lugar. Su lema es «Conocer para Viajar. Viajar para Aprender» (http://www.guisanteverdeproject.com).

\section{2. ¿Por qué estudiar la oralidad de los blogs?}

Existen cuatro tipos de blogs dedicados al turismo dependiendo de quién escribe: 1) personas anónimas (llamado «periodismo ciudadano»); 2) redes sociales para viajeros; 3) periodistas especializados, y 4) diarios de viaje creados por empresas turísticas. Los cuatro persiguen algo: unos buscan compartir su experiencia; otros, satisfacer a sus lectores y serles de utilidad, y otros, nuevos clientes.

Todos los expertos coinciden en señalar que los blogs de viajes han revolucionado el sector turístico, dado que -a diferencia de las agencias de viaje, que suelen maquillar sus ofertas- los blogs de viajes de personas anónimas son fuente de información para los potenciales consumidores turísticos que tienen a su disposición la experiencia de viajeros anónimos que narran en sus blogs todos los detalles (algunos muy personales) de su viaje, todos (los buenos y los malos, esos detalles que en cambio ocultan los mayoristas). Así, según el periodista M. Castells (2001: 48), «el éxito de estos blogs se debe a que Internet se trata de un medio de comunicación abierto donde no existe una estructura piramidal, porque todos somos iguales ante los ojos de Internet». En este sentido, según los periodistas López López y Ribera Martín (2010: 416), una de las grandes diferencias entre los blogs de viajes personales y los creados por empresas son los itinerarios alternativos y los precios del viaje. El viajero que no busca lucro en narrar su travesía es muy claro en cuanto a sus gastos, por ejemplo, cuánto ha costado un billete de autobús, una entrada a un museo, etc.

La revolución que han supuesto es tal, que las agencias intentan imitar el formato y el estilo de los blogs para captar nuevos clientes (López López y Ribera Martín, 2010: 416). Todos estos cambios y novedades se reflejan no solo en el tipo de discurso, sino también en la forma de comunicación, en el lenguaje. 
En este estudio se parte del presupuesto de que una cosa es el soporte o canal de comunicación (que puede ser oral o escrito), otra los registros (coloquial/formal), los géneros discursivos orales (monólogo, entrevista, debate, etc.) y un tercera la temática o tipos de discurso (conversacional, jurídico, turístico...). Se parte, por tanto, de la idea de que no todo lo oral es coloquial y no todo lo que es coloquial se desarrolla en el canal oral. Se verá más adelante qué se entiende por cada uno de estos conceptos.

\section{EL GÉNERO DEL BLOG TURÍSTICO}

Como hemos visto en la sección anterior, el formato de los blogs está siendo copiado por las agencias de viajes, sustituyendo en muchos casos a las guías de viaje. Llegados a este punto, podemos preguntarnos si un blog turístico es la versión web de las guías turísticas o de un libro de viajes.

A lo largo de la historia, dentro del marco de posibilidades que ofrecían la tecnología y los instrumentos en cada época determinada, los viajeros estaban interesados por transmitir y compartir experiencias vividas y que estas, de alguna manera, permanecieran en la memoria colectiva y sirvieran para la difusión del conocimiento. Estas motivaciones son las mismas que mueven al viajero hoy en día. El objetivo de hoy es el mismo: «compartir», porque como expresa Rivas (2006): «Narrar un viaje es algo connatural al propio viaje», o en palabras de Belenguer (2002: 14): «Viajar y contarlo después parece algo inseparable. Así lo han hecho todos, o casi todos los viajeros a lo largo de la historia».

Los libros de viajes conforman un género literario que ha gozado de una enorme popularidad durante siglos. Por lo general se entiende como «libro o diario de viajes» el relato no ficticio escrito en primera persona que describe un viaje a través de un país extranjero con observaciones sobre el paisaje, la geografía, la flora, la fauna, los habitantes, la historia y las costumbres del país. La obra que más ha contribuido a configurar el libro de viajes moderno y que ha generado el mayor número de imitadores ha sido el Libro de las maravillas del mundo, de Marco Polo.

Cuando se realizaba un viaje se llevaba un cuaderno de notas, donde se apuntaban todos los datos, sucesos, emociones y demás experiencias vividas. Luego se procesaban estas anotaciones y se elaboraba un texto. Esta técnica pervive en la actualidad, como lo hicieron en su día Heródoto o el propio Julio César, Hernán Cortés y tantos otros viajeros. Estas notas de viaje, que son textos de reducida extensión, se organizaban en sentido cronológico, de manera que cuando un viajero de la antigüedad comenzaba a anotar los sucesos del día, lo primero que escribía era la fecha o, en caso de ignorarla, al menos un sencillo «Día 6», por ejemplo. Hoy se sigue haciendo así. La aparición de Internet ha supuesto un nuevo soporte que encaja perfectamente con la lógica y la estructura del diario de viaje. Hoy, además, la crónica escrita puede acompañarse de otro tipo de contenidos, gracias a las novedosas herramientas de la web 2.0 para la creación, gestión y difusión de contenido como son fotografías y vídeos, mapas, infografías, etc., con la ventaja de que puede publicarse en cualquier momento, siempre y cuando se disponga de un ordenador y una conexión a Internet. Cabe destacar, además, 
que la interacción con el lector llega a su máxima expresión a través de comentarios, mensajes privados, chats y otras vías, que es la verdadera novedad del blog con respecto a los libros de viajes y con respecto a la guía.

Por otra parte, los blogs cumplen hoy día también la función de la guía de viaje, y es que, como indica Calvi (2006), el origen del turismo en sentido moderno y su desarrollo como actividad organizada se inicia en siglo XIX y está asociado, por consenso unánime, al desarrollo de un nuevo género textual: la guía de viaje, que es, a su vez, heredera de los libros de viajes, de los textos geográficos, y, por último, de los manuales para comerciantes y viajeros.

El género de las guías de viaje se alejó de la vertiente más literaria del libro de viaje sustituyendo la mirada personal por una visión pretendidamente objetiva. Hoy en día las agencias intentan imitar los blogs para hacer más atractivas sus ofertas. De este modo, con los blogs se vuelve al antiguo género ${ }^{2}$ de los libros de viajes que tuvieron su mayor auge en el pasado (y que fueron sustituidos por las guías de viajes).

Las guías de viajes se caracterizan por la función directiva e informativa, con un estilo impersonal, objetivo y descriptivo; en cambio, los blogs optan por el predominio de una función informativa con un estilo subjetivo.

\section{EL LENGUAJE DE LOS BLOGS DE TURISMO}

En este tipo de diarios hay tres tipos de lenguaje: textual, visual y audiovisual. El lenguaje textual es el predominante. Como ya se ha destacado anteriormente, donde parece radicar el éxito de los blogs es en el uso de un vocabulario sencillo y asequible a todos los públicos, por parte de los viajeros blogueros, a veces incluso con faltas de ortografía y puntuación, coloquialismos, vulgarismos y mucho humorismo (características, como veremos, del canal oral, del registro coloquial y del discurso conversacional).

${ }^{2}$ Siguiendo las diferentes definiciones de «género», Swales (1990), Bhatia (1993), Adam (2001), Loureda Lamas (2003: 37), el género es una clase, un modelo abstracto, paradigma de los caracteres necesarios de todos los textos de una misma naturaleza. Y aunque hay géneros con una elevada convencionalidad (jurídico, por ejemplo), en general son híbridos. Hoy en día la migración de los géneros a la web ha venido a perturbar una clasificación bastante estabilizada, determinando la recontextualización (Linell, 1998) de muchos géneros, rompiendo las convenciones y contribuyendo aún más a su hibridez. Siguiendo a Calvi (2010), los textos turísticos se pueden clasificar en: Familias de géneros: editoriales, institucionales, comerciales, organizativos, legales, científicos y académicos e informales. Los blogs turísticos son informales. Macrogéneros (identificables sobre todo por el emisor y el canal utilizado), guía de turismo, folleto, revista de viajes y turismo, catálogo de viajes, páginas web. Los blogs se corresponden con el último tipo. Géneros (nivel en el que se empiezan a discernir los rasgos lingüísticos distintivos): guía descriptiva, itinerario, guía práctica, programa de viaje, reportaje, anuncio, informe de turismo, billetes, reservas, contratos etc, normativas de turismo, foros de viajeros y blogs de viaje. Subgéneros: Clasificación realizada siguiendo una especificación temática. 


\subsection{Oralidad y escrituridad}

Como se ha señalado en más de una ocasión, hoy en día existe cada vez más la tendencia a la oralización y coloquización ${ }^{3}$ del texto escrito ${ }^{4}$. De todas formas, partimos de la idea de que la escritura y la oralidad no se contraponen necesariamente, aunque tradicionalmente hayan sido definidas de manera binaria: la oralidad como informal y la escritura como formal. En la comunicación oral intervienen elementos verbales y además paraverbales, como la entonación, el tono y el volumen de la voz (paralenguaje), y también extraverbales, como los gestos, los movimientos del cuerpo, las posturas físicas, las miradas y las distancias (proxémica), que faltan, evidentemente en los blogs, pero que, como se mostrará, trata de suplirse con algunas estrategias como el uso de emoticonos y con grafías especiales (uso de mayúsculas, repetición de vocales y consonantes o la repetición de signos ortográficos, por ejemplo).

El blog no posee los requisitos básicos del género conversacional (interlocución en presencia, inmediata, actual -aquí y ahora-; toma de turno no predeterminada, dinámica, sin tensión, dialógica; la relación hablante-oyente es simultánea y/o sucesiva; sin pares mínimos de intervenciones; cooperación en relación con el tema conversacional y con la intervención del otro) ${ }^{5}$. El blog no posee los requisitos prototípicos del registro coloquial (separación espacio-temporal entre emisor y destinatario, conocimiento personal, igualdad de roles en el género) ${ }^{6}$. Sin embargo, y como veremos en el análisis del corpus, los blogs poseen algunas características del discurso conversacional y muchas del registro coloquial.

Las conversaciones escritas por Internet permiten demostrar que entre el discurso oral y el discurso escrito no existe una oposición tajante. Según Koch y Oesterreicher (1985), las distintas modalidades de uso se sitúan en un continuum delimitado por dos polos extremos a los que denominan «inmediatez»y «distancia comunicativa». La diferenciación entre lo oral y lo escrito no constituye una dicotomía, sino una diferenciación gradual. También, Biber (1988) insistió en la idea de abandonar esta oposición y abordar el estudio del discurso desde una perspectiva «multidimensional». «La historia de los usos lingüísticos -en palabras de Bustos Tovar (1995: 18)- es el resultado de una tensión permanente entre oralidad y escrituridad, que es mutuamente enriquecedora». No puede hablarse, por tanto, de términos antagónicos, sino que habría que establecer dos extremos de gradación que comprenderían desde la escritura pura hasta la oralidad pura, donde existen zonas intermedias y situaciones más o menos híbridas. En una de esas situaciones híbridas, «en las que participan tanto elementos de la escritura como de la oralidad» (Bustos Tovar, 1997: 10), habría que colocar la

${ }^{3}$ Muchos de los textos de la literatura contemporánea imitan formas orales. Siempre lo hizo la novela, en los diálogos, por ejemplo, pero ahora, desde los textos de Joyce que carecen casi totalmente de puntuación, pasando por las novelas de Saramago donde se suprimen las marcas de diálogo, hoy muchos textos escritos se caracterizan sobre todo por el uso de un lenguaje cotidiano, que imita la oralidad (la llamada «oralidad ficticia»), lo que nos hace pensar en una intextualidad oralidad-escritura.

${ }^{4}$ Véase a este respecto, por ejemplo, Mancera (2009), sobre la oralización de la prensa escrita española.

${ }^{5}$ Briz (1998: 34-45) y Calsamiglia y Tusón (2007: 20).

${ }^{6}$ Briz (1998: 25-30 y 34-44) y Calsamiglia y Tusón (2007: 15-49). 
conversación escrita a través de Internet, que rompe la idea de que el discurso escrito se corresponde con un modo de expresión reflexivo y formal, mientras que el discurso oral se caracteriza por ser próximo, espontáneo y escasamente formal. Tendríamos, así, una variedad más de lo que Oesterreicher (1996) denomina «lo hablado en textos». La cuestión, sin embargo, es si se trata de una imitación de lo hablado, o estamos ante un nuevo género discursivo. A este respecto, Blanco (2002: 17) observa que «las nuevas tecnologías [...] han tenido como consecuencia la gestación de una nueva actividad comunicativa y un nuevo género discursivo, manifestación de lo hablado en lo escrito, que podemos calificar de conversación escrita». Lo evidente es que en estas conversaciones escritas la gente escribe como si hablara.

\subsection{Características lingüísticas del corpus}

Las características lingüísticas relacionadas bien con la coloquilidad, bien con la oralidad que se van a describir aquí están presentes en mayor o menor medida en los 25 blogs del corpus, dependiendo del estilo personal y del grado de formalidad de quien escribe.

\subsubsection{Estilo personal y subjetividad}

La subjetividad es una característica del género conversacional (Calsamiglia y Tusón, 2007). Como en la crónica y el reportaje, se da la noticia matizada por la visión personal del bloguero, favoreciendo la relación de familiaridad con el lector, lo que permite emitir juicios acerca de lo que escribe. Es verdad que todas las guías turísticas, en mayor o menor medida, comunican una visión del mundo y del viaje (Calvi, 2006: 23), pero en los blogs ello se lleva a su máxima expresión, pues su éxito se basa precisamente en eso: en una visión particular y subjetiva. Muy presente la función expresiva del lenguaje que Calsamiglia y Tusón (2007: 20-22) relacionan con las características prototípicas de la conversación oral, pues se manifiestan sentimientos a la vez que se intenta establecer un contacto con el otro. Mientras que la persona gramatical más característica o presente en las guías es la tercera del singular, la más frecuente en los blogs es la primera (egocentricidad del discurso conversacional), sobre todo con verbos de movimiento de percepción física o sensorial, como en las guías, pero en los blogs, además, son muy importantes los verbos de percepción emotiva:

El problema es que estoy en Alemania, a donde he venido en un minubetrip (tal vez lo recuerden de otros viajes, como el minubetrip a Israel del año pasado) con Ignacio, Zai y Guillermo para recorrer durante cinco días la zona del Mar del Norte. Son las siete de la mañana y dentro de una hora tengo que estar preparada para dar un paseo por el mercado de pescado y algún sitio más (www.trajinandoporelmundo.com).

A la subjetividad, característica de lo conversacional, se añade una característica temática típica de este discurso, como es el contar retazos o detalles de su vida personal, 
como en el primer post de los siguientes ejemplos, donde el bloguero viaja a Lisboa con su novia y cuenta, con todo lujo de detalles, cómo le pidió ser su esposa:

Lisboa es única, desde Baixa hasta el Barrio Alto, desde Chiado hasta la Alfama, parando antes en Belém para degustar unos deliciosos pastéis y seguir la marcha. Será por su pátina desgastada, el tranvía 28 escondiéndose detrás de la catedral o todas y cada una de las noches del miradouro de Santa Luzia donde a lo lejos se escucha un fado desgarrador. Por eso y muchas cosas más preparé un fin de semana especial para pasar con mi chica. Y por eso guardaba en el bolsillo un anillo de compromiso con el que pedirle a ella, a Rebeca, que se casara conmigo (www.elrincondesele.com).

La semana pasada pude reencontrarme de nuevo con uno de esos grandes lugares, se trataba de París, una capital a la que no volvía desde que a los quince años la visité con mis padres y hermano (www.ciudadanoenelmundo.com).

En muchas ocasiones los mismos blogueros se preguntan si no estarán contando demasiado de su vida personal. Incluso en uno la bloguera dedica un post entero a la digresión sobre los detalles personales y la privacidad en los blogs:

De todos estos motivos, el de la privacidad es con el que más me peleo. Cuando viajar es tu vida, y tu blog (por decisión personal) adopta la forma de «diario», en ocasiones resulta inevitable sentir ciertas dudas y temores: ¿Me estaré exponiendo demasiado? ¿Cómo hablo de esto sin mencionar esto otro? ¿Me arrepentiré algún día de lo que he escrito? ;Esto no quiero que lo sepa todo el mundo! (www.trajinandoporelmundo.com).

La subjetividad y egocentricidad está presente en la expresión libre de forma más o menos explícita de la ideología del autor (religiosa, política...):

Lo primero es que viajar a Irán ha superado todas mis expectativas, y vaya si eran altas. Nunca he creído en ejes malignos ni en las etiquetas, o más bien estigmas, que en muchas ocasiones se le coloca a ciertos lugares. Por ese lado no he pasado de creer que me encontraría una cara y ver definitivamente otra. Estaba convencido que la hospitalidad persa tantas veces reflejada por grandes viajeros era cierta. Nunca conviene olvidar que la gente de la calle es una cosa y los dirigentes están al otro lado. No se puede calificar a un pueblo por un régimen, y más si es tan anacrónico y perjudicial como es el que hace de Irán una República Islámica desde 1979 (http://www.elrincondesele.com).

Por otra parte, se expresan libremente emociones y sentimientos. Con respecto a las guías turísticas (véase Pérez Vázquez, 2011), notamos una frecuencia muy superior de predicados de percepción sensible e intelectual:

India es, para la mayoría de los viajeros, una apuesta de todo o nada. Aquí no valen medias tintas: o te entra en el corazón o te espanta. La segunda opción te hace querer salir huyendo y no volver nunca más; la primera no significa simplemente que te guste todo lo que ves, porque eso no es posible. Que te entre en el corazón significa que empiezas una relación en la que participan a la vez el amor y el odio, de la que muchas veces quieres salir pero a la que acabas volviendo. Es una fascinación en la que sabes que eres 
engañado, un encanto que en ocasiones es exasperante, un cabreo que se te va con ese balanceo suave de la cabeza de un niño que quiere decir sí (www.drymartinez.net).

Estaba a gusto. Feliz. No podía negarlo. Túnez me había sorprendido mucho y para bien. Mi primera impresión del país, hace ya un tiempo, en la que sólo pisé la capital homónima, había dejado en mi un poso bastante malo. Excesivamente turística, rediseñada para sacar el dinero de manera rápida y limpia a los turistas. Había perdido su personalidad comprada por el dinero que pudiera llegar. No les podía culpar, pero con esta visita relámpago se acabaron mis ganas de seguir conociendo el país (www.ignacioizquierdo.com).

En esta ocasión el viaje cruzaba por el interior, más al sur, atravesando el desierto. Desde el Mediterráneo hasta los muros del Atlas junto a la vecina Algeria. Tenía curiosidad por saber que nos depararía el viaje, por cruzar el desierto (www.ignacioizquierdo.com).

Se produce, como en la conversación oral, cambios de estilo y registros:

Pecado (latín peccātum) es la transgresión voluntaria de un precepto tenido por bueno. Viajero. Sí, tú. ¿Tienes un blog, no? Pues a ti me dirijo (www.viajesrockyfotos.com [17-03-2014]).

Al estilo personal se podría añadir (y esto no es una característica de la oralidad, sino todo lo contrario, de la falta de escrituridad) los errores tipográficos, las faltas de ortografía (sobre todo en tildes) y el poco uso o uso erróneo de los signos de puntuación.

\subsubsection{Función apelativa del lenguaje}

Además de la primera persona predominante en los blogs de turismo también resulta muy frecuente el «nosotros» inclusivo, que es muy utilizado en el lenguaje del turismo en las descripciones de los itinerarios (Calvi, 2006: 24), pero más frecuente aún es la segunda persona de plural (vosotros), como en los siguientes ejemplos, pues en los blogs, el diálogo, que sirve para potenciar el dinamismo, se establece con los lectores. De este modo, mientras que en la narración literaria la ausencia de receptor condiciona algunos procedimientos utilizados, en los blogs está presente en todo momento: aquí el lector suele sentirse interpelado y partícipe:

Pero volvamos a hablar sólo de viajes, de la capacidad de la eterna sorpresa que requiere conocer Irán (www.rincondesele.com).

Cuando estéis leyendo esta carta, estaré de nuevo en casa (www.rincondesele.com).

Os escribo, tras tres semanas descubriendo rincones y personas, mi última carta desde el Eje del bien antes de inmiscuirme en las rutinas de siempre y el calor confortable del hogar y la familia (www.rincondesele.com).

PD: Con internet funcionando a la perfección en mis equipos (la censura de los ayatolás no llega afortunadamente a España) vuelvo a dejarme ver por esas redes sociales 
como Twitter y Facebook que no he podido mantener en estos 21 días de viaje. Os he echado de menos pero reconozco que me ha venido bien desconectar y centrarme en lo verdaderamente importante (www.rincondesele.com).

Echad un ojo al mapa (pinchad sobre él para verlo más grande) (www.rincondesele.com).

El diálogo (propio de lo oral y lo conversacional) se establece también a través de preguntas retóricas, dirigidas al lector y con marcadores de retroalimentación, más típicos del discurso conversacional sincrónico que del asincrónico y escrito ${ }^{7}$. La apelación al «otro», la demanda de validación o evaluación de lo que se dice o los retroalimentadores se usan con una finalidad claramente interactiva (Schiffrin, 1987).

Nadie discute que los pescados atraviesan temporadas. Estados de gracia efímeros en los que su sabor es mejor que en otros meses del año. ¿Cuál es el momento óptimo de cada especie? (www.gastronotasdeCapel.com).

Viajero. Sí, tú. ¿Tienes un blog, no? Pues a ti me dirijo. Deja de mirar el Analytics de una vez y confiésate. ¿De verdad leíste aquél artículo que comentaste con un «está genial»? ¿En serio que nunca estando de mochilero has perjurado [...] (www.viajesrockyfotos.com [17-03-2014]).

La función apelativa del lenguaje se halla también con el imperativo y con perífrasis exhortativas, en segunda persona de singular o plural dirigidas a los lectores en plural o singular.

No se te ocurra ir con los tacones o con las zapatillas de deporte de suela plana que resbala más que las cáscaras de plátano en los cómics de Mortadelo y Filemón. Zapatillas de trekking, pantalones a ser posible impermeables, un pluma para el frío y una chaqueta con gorro para la humedad. No lleves la pedazo cámara réflex si no es absolutamente necesario, después de una hora de caminata sobre piedras con grandes desniveles y terreno abrupto, te acabará pesando. Utiliza una más pequeña o el propio móvil. Lleva lo imprescindible en una mochila pequeña, lo más ligero de equipaje posible (http://www.viajesrockyfotos.com).

${ }^{7}$ «A través de cualquier género electrónico puede llevarse a cabo una conversación por escrito más o menos interactiva, dependiendo del carácter sincrónico o asincrónico del canal» (López Quero, 2013: 78). Yus (2010: 178) señala el carácter sincrónico de la conversación escrita «porque ambos interlocutores se encuentran presentes (esto es, conectados a Internet) en el momento de la interacción». Otros, sin embargo, como Rintel y Pittam (1997), hablan de carácter asincrónico en tiempo simultáneo. López Quero (2003: 10) se refiere a un carácter sincrónico débil, «porque, aunque los interlocutores están presentes, la falta de sucesividad en la producción y recepción de mensajes resta, obviamente, sincronía a la interlocución virtual». 


\subsubsection{Tiempos verbales de la narración y del discurso conversacional}

En cuanto a los tiempos verbales, se usa el imperfecto para la narración del viaje y para las descripciones, que son subjetivas (esta última suele incluir emociones que provoca el paisaje o lo descrito en el autor). En general son de dos tipos: el paisaje (que suele realizarse en presente) y otra dinámica y expresionista en la que predominan las sensaciones, los sentimientos sobre la descripción. Como en las guías, se usa el indefinido para la narración de hechos históricos.

Se hace también uso del presente para la descripción, el llamado «gerundio de pie de página», donde el protagonista no es el paisaje, sino la actividad del viajero. Es típico del lenguaje periodístico, y también en la descripción de las fotografías que narran la actividad del viajero: $\underline{\text { Navegando }}$ por la noche por Kinabatangan (www.3viajes.com).

Como en la conversación, aparece la «narración dinámica» en el relato del viaje, en la que se acelera el ritmo narrativo dada por la acumulación de acciones mediante el empleo de muchas formas verbales. Las frases directas y breves permiten representar los pensamientos del narrador. Se utiliza un estilo vivo, impresionista, atento a los detalles significativos. Se intensifica de este modo la acción:

A veces cuesta arrancar. Esta vez me está costando bastante. Hace dos semanas que «estoy de viaje» y todavía no me siento de viaje. Estuve demasiado tiempo en Buenos Aires y me acostumbré a mi pequeña rutina porteña: escribir y editar el libro, mirar por la misma ventana hacia los mismos edificios, dormir en el mismo colchón todas las noches, hacerme el mismo desayuno todas las mañanas, salir a caminar por la ciudad con rumbo prefijado, hacer trámites, ir al taller de escritura, ir a la misma verdulería y comprar las mismas cosas para preparar las comidas de siempre, ensobrar libros y llevarlos al correo, tomarme siempre los mismos colectivos para ir a los mismos lugares, reunirme con mis amigas en cualquier momento, ver a mi familia cuando quisiera, soñar con viajar largo otra vez y esperar con paciencia a que llegara el momento (www.viajandoporahi.com).

\subsubsection{Léxico}

Se usan gran cantidad de coloquialismos y neologismos típicos del registro informal:

Me largo con Rebeca a pasar un fin de semana (www.elrincondesele.com).

Bocatas y agua. Entre esos elementos imprescindibles estarán un buen bocata y agua (fundamental) También podemos llevar alguna limonada tipo Aquarius que aporten sales minerales al cuerpo (www.viajesrockyfotos.com).

Se hallan gran cantidad de neologismos del lenguaje del turismo (como puenting o rafting) en el primer ejemplo e incluso formaciones neológicas personales del bloguero (ings y palabros en el primer y segundo ejemplo, respectivamente, o blogueril en el tercero), préstamos como shock en el cuarto ejemplo: 
Habrá embarazadas que prefieran tirarse en la playa y otras que quieran aprovechar una escapada urbana para ir a cenar y al teatro en previsión de los meses en los que igual no pueden hacerlo tanto. Los médicos y el sentido común no recomiendan destinos muy exóticos, con mucha altitud ni grandes aventuras que incluyan puenting, rafting y otros ings que requieran hiperventilar (http://blogs.elpais.com/turistario [14-05-2012]).

Entre los 'palabros' que pululan por la jerga turística (de la staycation al glamping) hay uno especialmente tierno: 'Babymoon'. Literalmente, luna de bebé, es un juego de palabras con 'honey moon', luna de miel en inglés (http://blogs.elpais.com/turistario [1405-2012]).

Lo cierto es que este es un sector (si se le puede llamar así) muy endogámico. Sólo nos interesa lo que publica nuestro compañero/rival blogueril. A ver qué dice y cómo lo dice. Pero ante todo buen rollismo (www.viajesrockyfotos.com [17-03-2014]).

Encontramos también vulgarismos (como en el primer y segundo ejemlo) y fraseología (en el tercer y cuarto ejemplo). Son también muy usados términos coloquiales (cochambroso y truquillos en los dos últimos ejemplos). Las expresiones idiomáticas, las frases hechas y las locuciones tienen en los intercambios orales e informales un gran peso, precisamente porque aportan expresividad y frescura popular a los enunciados (Ruiz Gurillo, 1998):

Ya se que suena a exabrupto del $23 \mathrm{~F}$ pero acabo de hospedarme en un hotel en Valencia, perteneciente a una cadena hotelera de las de siempre, con glamour y reformado hace poco. Me dieron lógicamente, la habitación adaptada y cuando vi el baño, me salió esta expresión «se sienten ¡coño!» (www.asaltodemata.com [23-02-2014]).

Y, ahora sí, después de esta paja mental (lo necesitaba para calentar, después de tanto tiempo sin escribir) este blog reanudará sus emisiones con un par de pequeños flashback, antes de continuar con Sri Lanka (http://trajinandoporelmundo.com [4-03-2014]).

Gudbjartur Jonsson, un granjero islandés extraordinariamente independiente y obstinado, que no duda en llevar a su familia por la calle de la amargura con el fin de cumplir su objetivo de levantar una granja sin ayuda de nadie (www.3viajes.com).

Durante la visita, se pasa por dos cuartos de tapices donde los tapices y alfombras dejan a todo el mundo con la boca abierta (www.3viajes.com).

A nivel de instalaciones y equipamientos no hemos de esperar grandes lujos, por lo general estamos hablando de casas de más de 150 años de antigüedad a las que se les ha hecho el mantenimiento justo. Nos encontraremos con moqueta en los lavabos, grifos separados para agua fría y caliente, cocinas de aspecto un poco cochambroso, etc. Pero una vez superado el shock inicial, estas diferencias formarán también parte de la experiencia de vivir en una sociedad distinta a la nuestra (www.3viajes.com [4-03-2014]). 
Estos y otros truquillos de supervivencia en Londres los iremos conociendo en siguientes entradas de la mano de nuestros jóvenes protagonistas. Stay tuned! (www.3viajes.com [4-03-2014]).

Son muy frecuentes las onomatopeyas y características de la entonación y pronunciación de la oralidad, que tratan de reproducirse en la escritura, como en los dos primeros ejemplos. Son también muy usadas las interjecciones propias de la lengua oral, como en los tres últimos ejemplos:

Al tercer desayuno ya he cojido confianza con sus dueños, Bechtold y Emmanuela Bumann y decido abordar con ellos la cuestión.

- ¿Os suena el nombre de Bárcenas?

-Barggggggsenessss??? Nou (www.viajesrockyfotos.com [4-10-2013]).

En esta placita, hay una curiosa figura de una pareja...... bailandoooo, mal pensados, jajaja bailandooo. ¡Qué romántico! (www.asaltodemata.com).

El otro estudio súper-revelador de la semana es uno realizado por el European Centre for Environment and Human Health. Su conclusión: A la gente le gusta ir a la playa. Ajá, gracias, ciencia social. Los estudiosos entrevistaron a 2.750 personas y descubrieron que en su mayoría preferían viajar a la playa que pasear por un parque urbano. Lo que no queda claro, dice el informe, es por qué. Más detalles, en la BBC (http://blogs.elpais.com/turistario [20-04-2012]).

Escribir diarios: Leer un diario es lo más aburrido del mundo, sólo superado por la lectura del reciente informe de la reforma fiscal. No creo que a nadie le importe a qué hora nos levantamos, qué desayunamos, si estabamos cansados o si fuimos al baño antes de salir de dejar el hotel. Sé que es una forma fácil, casi infantil, de contar historias pero tal vez hay que ser un poco original de vez en cuando para no caer en la simpleza. Y las fotos, ay, las fotos! (www.viajesrockyfotos.com [17-03-2014]).

Vaya este post como recuerdo y regalo a mi querida amiga María, con quien vivimos este «momento almodovar». Dos argentinas, libreta en mano, tomando clase «de mantilla» y aprendiendo de una sevillana de pura cepa, una de las tradiciones mas valoradas entre las mujeres de su tierra. ¿Ole por María, que desfiló «de mantilla» como una mas... y con acento argentino! Mi amiga volvió a Argentina, pero estoy segura que si lee ésto, le gustará recordar un retazo de esta hermosa tierra andaluza que, seguro, extraña un poquito (www.elproximoviaje.com [6-03-2014]).

Una característica de la escritura en las nuevas tecnologías que no se ha hallado en el corpus es la escritura fonética (por ejemplo aki por aquí)

Una característica de la oralidad es el uso de deícticos (Calsamiglia y Tusón, 2007; Briz, 1998). La falta de presencia física de los interactantes y el que no se compartan las mismas coordenadas espacio-temporales durante la conversación implican que la deixis predominante en las conversaciones escritas sea la espacial. La deixis mostrativa, la que hace referencia a la situación y más concretamente la denominada por Fernández Marcos (1990) deixis absoluta por la referencia implícita, es característica de la 
conversación escrita. De ahí que los estativos (aquí, allí y ahî)-sobre todo aquí- sean muy repetitivos

Diez años recién cumplidos desde que me instalé en la isla del hurling, la Guinness y el viento incesante, muchas son las imágenes que podrían sintetizar, sin palabras, sin necesidad de explicaciones, el por qué sigo aquí; pero de entre todas ellas me gustaría destacar éstas pertenecientes a un pequeño y recóndito lugar en el que no pasa nada pero donde pasa todo.

Éstas son algunas de las imágenes de mi paseo, de mi aventura, de mi historia. Éstas son las imágenes de Howth, Irlanda (www.viajablog.com [11-02-2014]).

Después de 7 años y más de 1.100 entradas publicadas, quienes nos leéis, aunque sea esporádicamente, sabéis que los artículos que publicamos no hablan siempre de escapadas o viajes turísticos de una o dos semanas; aquí también nos gusta tratar de viajes en el tiempo (historia y cultura), viajes introspectivos, y porqué no, de viajes hacia una nueva vida, como en el caso que nos ocupa (www.3viajes.com [4-03-2014]).

¿Por qué me gusta la Costa Brava? Mira... (www.elproximoviaje.com [19-07-2011]).

Otra característica de la lengua oral y de la coloquialidad son el tipo de nexos como «bueno», «claro», «hombre», «o sea», «vamos», «mira», «ahora», «oye»...

¿Cuántas fotos has hecho durante el viaje? Pues sinceramente ni idea porque las tengo repartidas por catálogos en discos duros y no he podido juntarlo todo todavía. Calculo que unas 200.000, pero vamos, a ojo de buen cubero (www.viajesrockyfotos.com [1-03-2011]).

Como conjunto Histórico Artístico me quedo con Cambados, la pena es que dejen aparcar por su casco antiguo, pero bueno, así pudimos entrar, aparcar y pasearlo con la silla de ruedas sin problemas (www.asaltodemata.com).

Todavía hay tiempo de votar a Viajando por ahí como Mejor Blog de Viajes en los Premios Bitácoras.com (¡vamos que ya estamos entre los Top 10!) (www.viajandoporahi.com [10-10-2011]).

¿Cuántas fotos has hecho durante el viaje? Pues sinceramente ni idea porque las tengo repartidas por catálogos en discos duros y no he podido juntarlo todo todavía. Calculo que unas 200.000, pero vamos, a ojo de buen cubero (www.viajesrockyfotos.com [1-03-2011]).

\subsubsection{Sintaxis}

Son muy frecuentes las repeticiones y reformulaciones, características de la oralidad y correcciones hasta que el que escribe encuentra la expresión que mejor se adapta a aquello que pretende comunicar: 
Está el Brasil blanco, al sur, y el Brasil negro, al norte. En la mayoría de ciudades se maneja a pequeña escala la misma división. Está el Brasil de los muy ricos y el Brasil de los muy pobres. Ahora también el Brasil de los que empiezan a hacer equilibrios entre esas dos realidades. Hay un Brasil donde habitan las poblaciones indígenas más ortodoxas del continente. Y también un Brasil con tantos rascacielos que podrían abrir la boca a un neoyorkino. Brasil de mar y Brasil de tierra. Brasil selva, brasil oficina. Existe un Brasil beato $y$ un Brasil de carnaval. Samba, violencia, amabilidad, peligro (http://blogs.elpais.com/kilometro-sur/ [26-02-2014]).

Nunca lo había pensado. O quizás sí. Pero tengo la impresión de que la ciudad más romántica del mundo es Lisboa. Siempre fiel a sí misma, dulce, melancólica y tan de verdad, que no se siente uno dentro de un decorado repetido (www.elrincondesele.com).

Nunca he creído en ejes malignos ni en las etiquetas, o más bien estigmas, que en muchas ocasiones se le coloca a ciertos lugares. Por ese lado no he pasado de creer que me encontraría una cara y ver definitivamente otra. Estaba convencido que la hospitalidad persa tantas veces reflejada por grandes viajeros era cierta (www.elrincondesele.com).

En general, en las formas más comunes y habituales de discurso oral se tiende al uso abundante de la yuxtaposición y la coordinación para relacionar oraciones y a un menor uso de nexos de subordinación (Calsamiglia y Tusón, 2007: 47). El predominio de la coordinación y la yuxtaposición sobre la subordinación en la lengua hablada la señala también Vigara Tauste (1996), entre otros. Si bien no se puede afirmar que esto sea una característica de los blogs dedicados al turismo, sino que depende en gran medida del estilo personal de quien escribe y de cada bitácora:

El vuelo del pardillo Cambridge (Inglaterra). Mi primer viaje al extranjero, yo era un pipiolo. Me esperaban en Heathrow y el avión aterrizó en Gatwick, tuve que buscarme la vida. A las 12 de la noche llamé al timbre de la casa donde iba a vivir más de un mes. Ya se habían acostado, y el landlord (casero) me señaló con desgana el camino a mi habitación - «upstairs» (en el piso de arriba)-. Aquel día no había comido, tampoco cené. Llovía, de eso sí me acuerdo (www.elviajeroastuto.com [25-09-2013]).

Por último, se hallan también numerosas construcciones sintácticas y giros típicos de la oralidad:

Estoy en Hamburgo. «¿Y a mi qué?», diréis, «Dedícate a escribir, que a este paso vas a terminar de contar tu viaje a Nueva Zelanda el día que los océanos se vacíen». Asumo toda la culpa.

No lleves la pedazo cámara réflex si no es absolutamente necesario, después de una hora de caminata sobre piedras con grandes desniveles y terreno abrupto, te acabará pesando. Utiliza una más pequeña o el propio móvil. Lleva lo imprescindible en una mochila pequeña, lo más ligero de equipaje posible (www.viajesrockyfotos.com).

La semana que viene se celebra Saint Patrick en Irlanda y desde Viajablog empezamos a calentar motores. No se si has vivido en alguna ocasión esta celebración. Si 
ya has tenido la suerte de hacerlo, no hace falta que te cuente cómo de loco se vuelve el país y la isla entera. Si no lo has hecho todavía, te lo recomiendo efusivamente. Saint Patrick es el día nacional de Irlanda, país católico que fue invadido durante casi 800 años por los ingleses y que recuperó la independencia tras siglos de lucha sin descanso y sin abandono. Hoy en día Irlanda es un país alegre y [...] (www.viajablog.com [14-03-2014]).

Por eso no hemos dudado en aprovechar la oportunidad de irnos unos días a Londres a conocer cómo viven allí varios jóvenes españoles que se liaron la manta a la cabeza hace unos meses, visto lo complicado de nuestro panorama laboral actual (www.3viajes.com [4-03-2014]).

Ser un turista: Resulta que si eres bloguero de viajes y eres turista, tu bitácora es un bluff, vamos que no merece ni siquiera ser leída. Sin embargo, si tienes un blog y eres un viajero, tu plataforma digital será una pasada, increible, ¡vaya historias!. Y es que eso los «expertos» lo notan. Eres un petardo que no te sabes ni siquiera explicar, escribes con faltas de ortografía, lo más cerca que estuviste de la palabra léxico fue cuando la confundiste con un tejido y tus fotos son horrorosas, pero eres un viajero. Guay. Yo, sin embargo, no soy auténtico porque viajo sin mochila, me alojo en lugares sin cucarachas y, siempre que puedo, intento que me paguen por mi trabajo. ¡Pero si ni siquiera salgo en ninguna foto! Menudo farsante. (www.viajesrockyfotos.com [17-03-2014]).

\section{oralidad}

3.2.6. Estrategias comunicativas de las nuevas tecnologías que tratan de suplir la

Los usuarios de Internet en las conversaciones escritas se sirven de ciertos recursos contextuales y expresivos que mitigan la falta de información extralingüística. Los blogs comparten el registro coloquial típico del género conversacional. Los emoticonos $^{8}$ suplen la emotividad, como estrategia de compensación de la información no verbal visual:

¡Cualquier recomendación para comer asados será más que bienvenida en los comentarios! (1) (www.3viajes.com [19-11-2012]),

Este blog reanudará sus emisiones con un par de pequeños flashback, antes de continuar con Sri Lanka, para recordar lo que ha ocurrido durante este febrero de silencio antes de llegar aquí. Próximamente (http://trajinandoporelmundo.com [4-03-2014]),

La «innovación tipográfica» dota al texto de una fuerte carga de oralidad (Reid, 1994; Ruedenberg et al., 1995; Watson, 1996), además de un evidente propósito lúdico (Kuehn, 1993). En cuanto a la grafía prosódica, las repeticiones de letras, el uso de

${ }^{8}$ Los emoticonos son representaciones gráficas convencionales, que representan gestos faciales, transmiten emociones o sentimientos de los usuarios. El 19 de septiembre de 1982, un investigador de informática llamado Scott Fahlman escribió: «Propongo :-) para las bromas. Léanlo de lado». Días después del comentario de Fahlman, afirma Avendaño (2012: 13), «la Universidad usaba :-) a diario. Al poco la de Stanford. Después se propagó por foros de varias instituciones. Era noviembre de 1982 y el emoticono, llamado a ser una de las linguas francas más universales, acababa de nacer». 
mayúsculas y otros signos de puntuación, etc., pueden ser un buen sustituto de la voz. Se trata, por tanto, de intensificadores, de estrategias conversacionales (López Quero, 2013: 84).

En esta placita, hay una curiosa figura de una pareja..... bailandoooo, mal pensados, jajaja bailandooo. iQué romántico! (www.asaltodemata.com).

Allí habíamos quedado con Ignacio, gerente de la empresa Queiles aventura una empresa multiaventura con una gran calidad en sus servicios y unos precios muy adecuados y que nos podemos permitir gastar a cambio de tener una experiencia que seguro recordaremos siempre. Os estareis preguntando... ¿Qué hicieron estos chic@s?, no os voy a hacer esperar más, y no os lo voy a contar, lo vais a ver. Deeeeeeeentrooooo vídeooooooooooooooos. (www.asaltodemata.com).

Querido Blog: Dormí menos de cuatro horas pero no me importa nada. Ayer vi la aurora boreal. Leíste bien: A-U-R-O-R-A-B-O-R-E-A-L. ¿Qué asunto mundano me puede importar después de haber visto algo así? (www.viajandoporahi.com [29-03-2012]).

Bueeeeeenas tardes damas y caballeros, señoras y señores, niños y gatos. En esta ocasión venimos a ofrecerles un producto fuera de serie, una promoción que no se pueden perder, ideal para el bolsillo de la dama y la cartera del caballero, perfecto para la mochila del viajero y para la mesa de luz del que todavía no partió (www.viajandoporahi.com [2903-2012]).

Sri Lanka no se parece en nada a India (repito: en naaaaaada, N-A-D-A. Y el que diga otra cosa no ha estado en uno de las dos) (www.trajinandoporelmundo.com [4-032014]).

Se hallan también numerosas repeticiones de los signos de interrogación e interjección, violando de este modo todas las normas académicas, pero que sustituyen la proxemia, típica de la oralidad:

¿Cuántas fotos has hecho durante el viaje? Pues sinceramente ni idea porque las tengo repartidas por catálogos en discos duros y no he podido juntarlo todo todavía. Calculo que unas 200.000 , pero vamos, a ojo de buen cubero.Por lo tanto, nos saldrían de media??? 375 lujosas fotos a todo color cada día. (www.viajesrockyfotos.com [1-03-2011]).

El jueves es el día de Hanuman (el dios mono) y desde las ocho hasta las doce de la noche, en una capilla situada debajo mismo de mi almohada, un grupo de hombres y niños se dedicaron a repetir a saber qué mantras marcando el ritmo con unos tambores. Una de esas (recurrentes) situaciones en las que piensas: "iiiLes quiero matar!!!», para después echarte a reír histéricamente porque sabes que no hay solución posible (www.trajinandoporelmundo.com). 


\section{CONCLUSIONES}

Como muestran los expertos, la escrituridad muestra cada vez más rasgos de la oralidad, en especial en la comunicación producida en las nuevas tecnologías.

En el estudio se ha mostrado que desde el punto de vista lingüístico los textos de blogs poseen características del discurso conversacional, a pesar de que este es típico de los géneros sincrónicos (comunicación en presencia de los interlocutores, simultáneamente), que en cambio en los blogs se produce en acronía. Por otra parte, estos sitios poseen numerosas características de la comunicación en el canal oral, a pesar de que el soporte es escrito, y numerosas características del registro coloquial.

Como se ha mencionado, las agencias de viajes están copiando y tratando de reproducir el formato del blog para sus ofertas turísticas. En una futura investigación sería interesante comparar la fingida oralidad de los blogs de las agencias con la de los blogs personales

\section{REFERENCIAS BIBLIOGRÁFICAS}

ADAM, Jean Michel (2001): Linguistique textuelle. Des genres de discours aux textes, París, Nathan.

Álvarez Nobell, Alejandro (2010): «El periodismo digital como escenario para la publicidad contextual», en Sabés Turmo, Fernando y José Juan Verón Lassa, eds., El periodismo digital desde la perspectiva de la investigación universitaria. XI Congreso de Periodismo Digital de Huesca, Zaragoza, Asociación de la prensa de Aragón.

Avendaño, Tom C. (2012): «30 años de Emoticonos», El País Semanal, 28 de octubre, 12-13.

Belenguer Jane, Mariano (2002): Periodismo de Viajes: Análisis de una Especialización Periodística, Sevilla, Comunicación Social, Ediciones y Publicaciones.

BhatiA, Vijay K. (1993): Analysing Genre: Language in Professional Settings, London, Longman.

BIBER, Douglas (1988): Variation across speech and writing. Cambridge, Cambridge University Press.

BLANCHE-BENVENISTE, Claire (1998): Estudios lingüísticos sobre la relación entre oralidad y escritura, Barcelona, Gedisa. Ariel.

BRIZ GóMEZ, Antonio (1998): El español coloquial en la conversación, Barcelona,

Calsamiglia, Helena (1994): «El estudio del discurso oral». Signos. Teoría y práctica de la educación, 12, 18-28.

CAlsamiglia, Helena y Amparo Tusón (2001): Las cosas del decir, Barcelona, Ariel.

CALVI, Maria Vittoria (2006): Lengua y comunicación en el español del turismo, Madrid, Arco/Libros. 
CALvi, Maria Vittoria (2010): «Los géneros discursivos en la lengua del turismo: una propuesta de clasificación», Ibérica, 19, 9-32 [en línea]: 〈http://www.aelfe.org/documents/01_19_Calvi.pdf $>$.

DUFFY, Peter y Axel BRUNS (2006): «The Use of Blogs, Wikis and RSS in Education: A Conversation of Possibilities», Proceedings Online Learning and Teaching Conference 2006, Brisbane.

Henning-Thurau, Thorsten, Kevin P. Gwinner, Gianfranco Walsh y Dwayne GREMLER (2004): «Electronic word of mouth via consumer-opinion platforms», Journal of Interactive Marketing.

Koch, Peter y Wulf OESTERREICHER (1985): «Sprache der Nähe -Sprache der Distanz. Mündlichkeit und Schriftlichkeit im Spannungsfeld von Sprachtheorie und Sprachgeschichte», Romanistisches Jahrbuch, 36, 15-43.

LiNELL, Per (1998): «Discourse across Boundaries: On Recontextualizations and the Blending of Voices in Professional Discourse», Text, 18, 2: 143-157, $\langle$ http://dx.doi.org/10.1515/text.1.1998.18.2.143〉 .

LÓPEZ QUERO, Salvador (2003): El lenguaje de los 'chats'. Aspectos gramaticales, Granada, Port-Royal Lingüística.

LÓPEZ QUERO, Salvador (2013): «La conversación escrita en Internet: caracterización pragmalingüística», Sintagma, 25, 77-92.

LÓPEZ SERENA, Araceli (2007): Oralidad y escrituralidad en la recreación literaria del español, Madrid, Gredos.

LOUREDA LAMAS, Óscar (2003): Introducción a la tiplogía textual, Madrid, Arco/Libros.

MANCERA RUEDA, Ana (2009): Oralización de la prensa española: la columna periodística, Oxford, European University Studies.

OESTERREICHER, Wulf (1996): «Lo hablado en lo escrito: reflexiones metodológicas y aproximación a una tipología», en Kotschi, Thomas, Wulf Oesterreicher y Klaus Zimmermann, eds., El español hablado y la cultura oral en España e Hispanoamérica, Fráncfort del Meno, Vervuert, 317-340.

ONG, Walter J. (1982 [2006]): Oralidad y escritura. Tecnologías de la palabra, Buenos Aires, Fondo de Cultura Económica.

PÉreZ VÁZQUeZ, M. a Enriqueta (2011): «Verbos de percepción sensible e intelectual en las guías y en la publicidad turística», en Calvi, Maria Vittoria y Giovanna Mapelli, eds., La lengua del turismo. Géneros discursivos y terminología, Milán, Peter Lang, 295-314.

REID, Elisabeth M. (1994): Cultural Formations in Text-Based Virtual Realities, Universidad de Melburne.

RINTEL, E. Sean y Jeffery PITTAM (1997): «Strangers in a strange land: Interaction management on internet Relay Chat», Human Communication Research, 23, 4, 507 534, <http://dx.doi.org/10.1111/j.1468-2958.1997.tb00408.x >.

RIVAS, Eduardo (2006): Historia y Naturaleza del periodismo de viajes: Desde el Antiguo Egipto hasta la Actualidad, Madrid, Miraguano ediciones.

RUEDENBERG, Lucia, Brenda DANET y Yehudit RoSENBAUM-TAMARI (1995): «Virtual virtuosos: Play and performance at the computer keyboard», Electronic Journal 
of Communication [en línea]: 〈http://www.cios.org/EJCPUBLIC/005/4/00542.HTML>.

RUIZ GURILlO, Leonor (1998): La fraseología del español coloquial, Barcelona, Ariel.

SABÉS TURMO, Fernando y José Juan Verón LASSA, eds. (2010): El periodismo digital desde la perspectiva de la investigación universitaria. XI Congreso de Periodismo Digital de Huesca, Zaragoza, Asociación de la prensa de Aragón.

SCHIFFRIN, Deborah (1987): Discourse Markers. Cambridge, Cambridge University Press.

SCHOECKEL, Alonso (1972): La formación del estilo, Santander, Sal terrae.

SwALES, John (1990): Genre Analysis, Cambridge, Cambridge University Press.

Tusón, Amparo (1991): «Las marcas de la oralidad en la escritura», Signos. Teoría y práctica de la educación, 12, 14-19.

VARELA, Juan (2005): «Periodismo 3.0. La socialización de la información». Periodistas, 21 [en línea]: 〈http://periodistas21.eapuntes.com/index.php/Portada $>$.

Vigara TAuste, Ana María (1996): «Español coloquial: expresión del sentido por aproximación», en Kotschi, Thomas, Wulf Oesterreicher y Klaus Zimmermann, eds., El español hablado y la cultura oral en España e Hispanoamérica, FráncfortMadrid, Vervuert-Iberoamericana.

WATSON, AnnMarie. (1996): «Formality of computer-mediated communication between faculty and students», CTA Senior Thesis Papers [en línea]: <http://people.wcsu.edu/ mccarneyh/acad/watson.html $>$.

Yus, Francisco (2010): Ciberpragmática 2.0. Nuevos usos del lenguaje en internet, Barcelona, Ariel. 